\title{
Is there an association between food portion size and BMI among British adolescents?
}

\author{
Salwa A. Albar ${ }^{1,2 *}$, Nisreen A. Alwan ${ }^{1}$, Charlotte E. L. Evans ${ }^{1}$ and Janet E. Cade ${ }^{1}$ \\ ${ }^{1}$ Nutritional Epidemiology Group, School of Food Science and Nutrition, Room G.07, Food Science Building, \\ University of Leeds, Leeds LS2 9JT, UK \\ ${ }^{2}$ School of Food Science and Nutrition, King Abdul-Aziz University, PO Box 42807, Jeddah 21551, Saudi Arabia \\ (Submitted 12 January 2014 - Final revision received 11 April 2014-Accepted 22 May 2014 - First published online 7 July 2014)
}

\section{Abstract}

The prevalence of obesity has increased simultaneously with the increase in the consumption of large food portion sizes (FPS). Studies investigating this association among adolescents are limited; fewer have addressed energy-dense foods as a potential risk factor. In the present study, the association between the portion size of the most energy-dense foods and BMI was investigated. A representative sample of 636 British adolescents (11-18 years) was used from the 2008-2011 UK National Diet and Nutrition Survey. FPS were estimated for the most energy-dense foods (those containing above $10.5 \mathrm{~kJ} / \mathrm{g}(2.5 \mathrm{kcal} / \mathrm{g})$ ). Regression models with BMI as the outcome variable were adjusted for age, sex and misreporting energy intake (EI). A positive association was observed between total EI and BMI. For each $418 \mathrm{~kJ}$ $(100 \mathrm{kcal})$ increase in EI, BMI increased by $0 \cdot 19 \mathrm{~kg} / \mathrm{m}^{2}(95 \% \mathrm{CI} 0 \cdot 10,0 \cdot 28 ; P<0 \cdot 001)$ for the whole sample. This association remained significant after stratifying the sample by misreporting. The portion sizes of a limited number of high-energy-dense foods (high-fibre breakfast cereals, cream and high-energy soft drinks (carbonated)) were found to be positively associated with a higher BMI among all adolescents after adjusting for misreporting. When eliminating the effect of under-reporting, larger portion sizes of a number of high-energy-dense foods (biscuits, cheese, cream and cakes) were found to be positively associated with BMI among normal reporters. The portion sizes of only high-fibre breakfast cereals and high-energy soft drinks (carbonated) were found to be positively associated with BMI among underreporters. These findings emphasise the importance of considering under-reporting when analysing adolescents' dietary intake data. Also, there is a need to address adolescents' awareness of portion sizes of energy-dense foods to improve their food choice and future health outcomes.

\section{Key words: Food portion sizes: Energy-dense foods: BMI: Adolescents}

The prevalence of obesity has increased all over the world, particularly in England, where it has more than doubled in the last 25 years. In 2011, three in ten boys and girls were classified as overweight or obese (31 and $28 \%$, respectively) ${ }^{(1)}$. Obesity is considered to have adverse implications for health, with a higher risk of morbidity and mortality as obese adolescents become obese adults ${ }^{(2)}$. Although weight gain is commonly understood to be a result of the balance between what people eat and how much they exercise ${ }^{(3)}$, growing research points to food intake as the primary cause of the obesity epidemic ${ }^{(4)}$. As such, there is an urgent need to identify important nutrition-related risk factors for obesity ${ }^{(5)}$.

Many dietary factors can directly or indirectly influence the balance of energy intake (EI) and thus affect weight gain ${ }^{(3)}$. However, evidence regarding specific dietary factors that promote weight gain in children and adolescents is more limited than that for adults ${ }^{(6)}$. Total grams of foods, sweetened beverages, sweets, and low-nutrient foods and portion size consumed during dinner are the main determinants of obesity in American young people according to one study ${ }^{(7)}$. The last decade has witnessed marked increases in the portion sizes of many foods. According to data from the US Nationwide Food Consumption Survey, between 1977 and 1998, the energy content of salty snacks has increased by $389 \mathrm{~kJ}$ ( $93 \mathrm{kcal}$ ), soft drinks by $205 \mathrm{~kJ}$ ( $49 \mathrm{kcal}$ ), hamburgers by $406 \mathrm{~kJ}$ (97 kcal), and French fries by $285 \mathrm{~kJ}$ ( $68 \mathrm{kcal})$ per portion ${ }^{(8)}$. A similar trend in food portion sizes (FPS) consumption has also been observed in the Netherlands ${ }^{(9)}$ and the $\mathrm{UK}^{(10,11)}$, but there is less direct evidence from these countries.

As the trend of consuming larger food portions has occurred at the same time as the increase in the prevalence of obesity, investigation of FPS as a potential health risk factor leading to obesity is required $^{(12)}$. It is often assumed that obese adolescents eat more fast foods and energy-dense foods than normal-weight adolescents. However, there is little evidence to support this belief ${ }^{(13,14)}$.

Abbreviations: EI, energy intake; FPS, food portion size; NDNS, National Diet and Nutrition Survey.

*Corresponding author: S. A. Albar, fax +44 113343 2982, email ml09saa@leeds.ac.uk; salbar1@kau.edu.sa 
The energy density of food is defined as the number of $\mathrm{kJ}$ in a given weight of food $(\mathrm{kJ} / \mathrm{g})^{(15)}$. The World Cancer Research Fund $\mathrm{UK}^{(16)}$ has classified foods that contain more than $941-1151 \mathrm{~kJ} / 100 \mathrm{~g}(225-275 \mathrm{kcal} / 100 \mathrm{~g})$ as high-energydense foods, normally due to high fat and/or sugar content and low fibre and water content. Foods that contain $418-941 \mathrm{~kJ} / 100 \mathrm{~g}(100-225 \mathrm{kcal} / 100 \mathrm{~g})$ are defined as mediumenergy-dense foods and foods that contain $251-628 \mathrm{~kJ} / 100 \mathrm{~g}$ $(60-150 \mathrm{kcal} / 100 \mathrm{~g})$ are defined as low-energy-dense foods. Larger portion sizes of energy-dense foods are more likely to increase EI beyond requirements ${ }^{(17,18)}$. Furthermore, the high palatability of energy-dense foods may lead to greater consumption of these foods ${ }^{(14)}$.

Several experimental studies have provided evidence for a relationship between FPS and $\mathrm{EI}^{(17-19)}$; however, epidemiological studies on the relationship between FPS and weight gain are limited ${ }^{(12,20)}$, particularly among adolescents ${ }^{(5)}$. Some studies have considered only snack foods ${ }^{(21)}$, fast foods or sugar-sweetened beverages ${ }^{(22,23)}$, while some have investigated the general trends of FPS over time ${ }^{(10,24)}$. Epidemiological studies that address the association between highenergy-dense foods and weight gain need to be examined ${ }^{(20)}$. Although cross-sectional studies by their nature cannot prove causality, use of nationally representative data with adjustment for potential confounders can provide useful information on the relationships between diet and health where longitudinal and trial data are unavailable ${ }^{(12-14,23)}$. Therefore, the present study is the first to assess the association between portion sizes of energy-dense foods and BMI among British adolescents aged 11-18 years using data from the newly updated National Diet and Nutrition Survey (NDNS) for 3 years combined (from 2008 to 2011).

\section{Methodology}

\section{National Diet and Nutrition Survey data}

NDNS data were obtained from the UK Data Archive, University of Essex ${ }^{(25)}$. The NDNS data on adolescents aged $11-18$ years are part of a rolling programme of government-commissioned surveys of different age groups of the free-living British population. This cross-sectional survey has an advanced sample design intended to obtain a nationally representative sample of British adolescents. The survey design and sampling framework have been described in greater detail in published reports $^{(26)}$. A total of 666 adolescents participated in the NDNS from 2008 to 2011 (218, 222 and 196 in each year, respectively). Of these participants, twenty (3\%) were excluded as their weight or height was not reported and ten (2\%) were excluded due to reporting being on a weight-loss diet during the study and thus potentially avoiding the intake of highenergy foods. The final sample included 636 respondents.

\section{Dietary methods}

A 4 d estimated food diary was used in the 2008-2011 NDNS. Adolescents aged $\geq 12$ years were encouraged to complete the diary by themselves. The participants were asked to keep a record of everything eaten or drunk over four consecutive days at home and away from home using household measurements (pictures of actual size spoons and glasses were provided to aid accurate recording). Also, to enhance the accuracy of the estimation of FPS, a young person's photo food atlas ${ }^{(27,28)}$ was used for the group that reported its dietary intake in 2010-2011. Trained interviewers demonstrated procedures and visited each participant three times to review the diary, deal with problems, and edit possible omissions and missing details. In the 2008-2011 NDNS, food items were categorised into one of the ten food types, fifty food groups and 140 subfood groups; details regarding the components of each category have been published in previous reports ${ }^{(29)}$. The top twenty high-energy-dense subfood groups (from here on referred to as food groups) were used to calculate FPS, and these are defined in online supplementary Appendix 1. Food and nutrient intakes were calculated based on McCance and Widdowson's Composition of Food series (6th edition) $)^{(30)}$ and manufacturers' data where applicable ${ }^{(26)}$.

\section{Food portion size}

In the present study, the method used by Wrieden et al. ${ }^{(31)}$ was followed to calculate FPS. For each participant, the mean portion size of each food group was calculated by dividing the total weight of the food consumed by the frequency of consumption. So each subject contributed a single portion weight to avoid the possibility of participants who eat a certain food more frequently than others skewing the data ${ }^{(31)}$. For example, if participants consumed white bread two times on the 1st day and three times on the 2 nd day, then the total grams of white bread consumed over the $2 \mathrm{~d}$ would be divided by 5 .

\section{Energy-dense food}

To determine the energy density of food groups, the total energy of each food group portion was divided by total grams of food consumed ${ }^{(15,32)}$. Food groups that contained above $10 \cdot 5 \mathrm{~kJ} / \mathrm{g}$ (at least $2.5 \mathrm{kcal} / \mathrm{g}$ ) were used in the present study as a cut-off point based on World Cancer Research Fund classification and beverages that contained $>1.7 \mathrm{~kJ} / \mathrm{ml}$ (at least $0.4 \mathrm{kcal} / \mathrm{ml}$ ) were the focus of the analysis.

Although beverages contain less energy per $\mathrm{ml}$ (it is known that water has the greatest impact on the energy density of foods, adding substantial weight without adding energy ${ }^{(18)}$ ), they too were tested, due to their contribution to adolescents' total EI being high, at 9\% according to the 2008-2011 NDNS (SA Albar, NA Alwan, CEL Evans and JE Cade, unpublished results). All types of fats (polyunsaturated oils, cooking fats and oils (not PUFA), butter, reduced-fat spreads (not PUFA) and low-fat spreads (polyunsaturated)) were combined together in one food group as the number of adolescents consuming individual items from this food group was small.

\section{Anthropometric measurements}

The height and weight of the participants were measured to the nearest $0 \cdot 1 \mathrm{~cm}$ and $\mathrm{kg}$ by trained interviewers. BMI was calculated 
using Quetelet's formula (weight $(\mathrm{kg}) /$ height $\left(\mathrm{m}^{2}\right)$ ). BMI was classified on the basis of the growth values of UK children (UK 1990 reference values). Adolescents were classified as obese if their BMI was $>95$ th centile and overweight if their BMI was $>85$ th and $\leq 95$ th centiles according to sex and age ${ }^{(33)}$.

\section{Misreporting}

To reduce the impact of misreporting EI on the association between FPS and BMI, misreporting was calculated. It was based on the principle that an individual of a given sex, age and body weight has a minimum EI and that an intake below this EI has adverse effects on habitual intake and long-term survival. The body weight of adolescents was used to determine their BMR using the standard equations of Schofield ${ }^{(34)}$ for each sex. Cut-off points based on multiples of BMR with minimum (1.39 and 1.30) and maximum (2.24 and 2.10) cut-off points $(\mathrm{MJ} / \mathrm{d})$ for males and females, respectively, were used to identify probable under-reporters. These cut-offs were proposed by Torun et $a l .{ }^{(35)}$ for use among adolescents. This was considered to be the most practical and suitable approach due to there being no data available regarding the physical activity of adolescents.

\section{Statistical analyses}

Analyses were carried out using Stata statistical software release 12 (Stata Corporation), with a $P$ value $<0.05$ representing statistical significance for all tests. Descriptive statistics were used to describe general characteristics, EI and macronutrient intake, and FPS for all adolescents and the whole sample stratified by weight status.

The association between BMI as a continuous variable and total EI and macronutrient intake was investigated, adjusting for important confounders (age, sex and misreporting EI) using multivariable regression (model 1).

Multivariable regression analysis was carried out using FPS for each energy-dense food group to investigate the association between BMI as the dependent variable and FPS as the independent variable, adjusting for age, sex and misreporting (model 2). A stratified analysis was also carried out, splitting the sample into two groups, normal reporters and under-reporters (model 3), to determine any potential effect of under-reporting on the associations under investigation.

\section{Results}

\section{Sample characteristics}

A total of 636 adolescents aged 11-18 years were included in the study. The majority ( $88 \%$ ) were of White European origin. The average age of the participants was 15 years, and $52 \%$ were males. Among those included, $2 \%$ were vegetarians (Table 1). An association between BMI, age and sex was observed. When age increased by 1 year, BMI increased by $0.45 \mathrm{~kg} / \mathrm{m}^{2}$ (95\% CI 0.31, 0.59; $P<0.001$ ). The BMI of females was greater than that of males by $0.89 \mathrm{~kg} / \mathrm{m}^{2}(95 \%$ CI $0.21,1.56 ; P<0 \cdot 01)$ The percentage of misreporting was high at $73 \%$.

Table 1. General characteristics and dietary intake of all adolescents (11-18 years) who participated in the National Diet and Nutrition Survey

(Mean values and $95 \%$ confidence intervals)

\begin{tabular}{|c|c|c|c|c|c|c|}
\hline & \multicolumn{2}{|c|}{$\begin{array}{l}\text { All adolescents } \\
\qquad(n 636)\end{array}$} & \multicolumn{2}{|c|}{$\begin{array}{c}\text { Normal-weight } \\
\text { adolescents }(n 418)\end{array}$} & \multicolumn{2}{|c|}{$\begin{array}{l}\text { Overweight and obese } \\
\text { adolescents }(n 218)\end{array}$} \\
\hline & Mean & $95 \% \mathrm{Cl}$ & Mean & $95 \% \mathrm{Cl}$ & Mean & $95 \% \mathrm{Cl}$ \\
\hline \multicolumn{7}{|l|}{ General characteristics } \\
\hline Age (years) ${ }^{\star}$ & $14 \cdot 6$ & $14 \cdot 4,14 \cdot 8$ & $14 \cdot 8$ & $14 \cdot 6,15$ & $14 \cdot 2$ & $13 \cdot 9,14.5$ \\
\hline Height $(m)$ & $164 \cdot 2$ & $163 \cdot 3,165$ & $164 \cdot 4$ & $163.4,165.5$ & $163 \cdot 6$ & $162 \cdot 2,165$ \\
\hline Weight (kg) & $59 \cdot 3$ & $58 \cdot 1,60 \cdot 5$ & 53.5 & $52 \cdot 5,54 \cdot 6$ & 70.5 & $68 \cdot 3,72 \cdot 6$ \\
\hline BMI $\left(\mathrm{kg} / \mathrm{m}^{2}\right)$ & $21 \cdot 8$ & $21 \cdot 5,22 \cdot 1$ & $19 \cdot 6$ & $19 \cdot 4,19 \cdot 8$ & $26 \cdot 1$ & $25 \cdot 5,26 \cdot 6$ \\
\hline Waist circumference & $57 \cdot 1$ & $54 \cdot 4,59 \cdot 7$ & $53 \cdot 1$ & $49 \cdot 9,56 \cdot 2$ & 64.8 & $59 \cdot 7,69.9$ \\
\hline Female $(\%)$ & 48.4 & $45 \cdot 0,52 \cdot 3$ & $47 \cdot 6$ & $42 \cdot 8,52 \cdot 4$ & $50 \cdot 0$ & $43 \cdot 3,56 \cdot 6$ \\
\hline \multicolumn{7}{|l|}{ Ethnicity } \\
\hline White (\%) & $88 \cdot 2$ & $85 \cdot 6,90 \cdot 7$ & $87 \cdot 1$ & $83 \cdot 8,90 \cdot 3$ & $90 \cdot 4$ & $86.4,94.3$ \\
\hline Vegetarian (\%) & $2 \cdot 0$ & $0.9,3.1$ & $2 \cdot 2$ & $0.7,3.5$ & 1.8 & $0.03,0.04$ \\
\hline Under-reporter $\mathrm{El}^{*}(\%)$ & $73 \cdot 1$ & $69 \cdot 7,76 \cdot 5$ & $66 \cdot 3$ & $61 \cdot 7,70 \cdot 8$ & $86 \cdot 2$ & $81 \cdot 6,90 \cdot 8$ \\
\hline \multicolumn{7}{|l|}{ Dietary characteristics } \\
\hline \multicolumn{7}{|l|}{ Total energy } \\
\hline kcal & 1798 & 1759,1837 & 2251 & 2183,2319 & 1633 & 1596,1669 \\
\hline kJ & 7573 & 7411,7736 & 7654 & 7458,7849 & 7419 & 7127,7712 \\
\hline Protein $(\mathrm{g})$ & 66 & $64 \cdot 6,67 \cdot 7$ & $66 \cdot 6$ & $65,68.5$ & 65 & 63,68 \\
\hline Percentage of energy from protein & 15 & 15,15 & 15 & $14 \cdot 5,15$ & 15 & $14 \cdot 7,15 \cdot 5$ \\
\hline Fat $(\mathrm{g})$ & 68 & 66,70 & $68 \cdot 9$ & 67,71 & 66 & 63,69 \\
\hline Percentage of energy from fat & 34 & 34,34 & 34 & 34,35 & 34 & 33,34 \\
\hline Carbohydrates (g) & 241 & 235,246 & 243 & 237,250 & 236 & 227,245 \\
\hline Percentage of energy from carbohydrates & 50 & 50,51 & 50 & 50,51 & 50.5 & 50,51 \\
\hline Total sugars $(\mathrm{g})$ & 105 & 101,108 & 107 & 102,111 & 101 & 95,107 \\
\hline Percentage of energy from total sugars & 22 & 21,22 & 22 & 22,23 & 21 & 21,22 \\
\hline
\end{tabular}

El, energy intake.

* Significant differences between normal-weight and overweight adolescents $(P<0.01)$.

$\dagger$ Significant differences between normal-weight and overweight $(P<0.001)$. 


\section{Association between $\mathrm{BMI}$ and energy intake}

The total mean EI of UK adolescents aged 11-18 years was $7527 \mathrm{~kJ} / \mathrm{d} ; 95 \%$ CI $7364,7686 \mathrm{~kJ}(1799 \mathrm{kcal} / \mathrm{d} ; 95 \%$ CI 1760 , $1837 \mathrm{kcal})$. A significant association was observed between total EI (kJ) and BMI after adjusting for age, sex and misreporting EI. For each additional $418 \mathrm{~kJ}(100 \mathrm{kcal})$ in the adolescent diet, BMI increased by $0 \cdot 19 \mathrm{~kg} / \mathrm{m}^{2} \quad(95 \%$ CI $0 \cdot 10,0 \cdot 28$; $P<0.001)$. After stratifying the sample by normal reporters and under-reporters, a significant association was observed between EI and BMI in both groups, but the association was stronger among normal reporters (Table 2).

There was a significant positive association between BMI and intake of protein, fat, carbohydrates and total sugars among all adolescents and normal reporters. The association was stronger among normal reporters than in the whole sample. However, the association was only significant for total EI among under-reporters.

\section{Association between $B M I$ and portion size of the most energy-dense foods}

In the NDNS, twenty food groups were defined as energy dense, with a minimum density of $10.5 \mathrm{~kJ} / \mathrm{g}(2.5 \mathrm{kcal} / \mathrm{g})$. Half of these foods (ten food items) were considered as foods that are commonly consumed by adolescents (Fig. 1). At least $20 \%$ of the sample consumed these foods. The mean and $95 \%$ CI of each FPS are summarised in Table 3 for all adolescents, normal-weight adolescents and overweight/obese adolescents. The average portion size of some energy-dense foods such as chocolate confectionery, 'buns cakes and pastries' (from here on referred to as cakes) and cheese was found to be higher among normal-weight adolescents than among overweight/obese adolescents.

A positive association was observed between portion size and BMI for a number of energy-dense foods (Table 4). For the whole sample, the portion sizes of only two food groups, cream and high-fibre breakfast cereals, were positively associated with a higher BMI after adjusting for age, sex and misreporting. The number of food groups significantly associated with BMI was higher among normal reporters, with a significant positive association being observed for four of the top twenty energy-dense food groups. The portion sizes of biscuits, cheese, cakes and cream were significantly associated with BMI. For example, for each $10 \mathrm{~g}$ of biscuits, cheese or cakes consumed, BMI increased by $0.28,0.26$ and $0.19 \mathrm{~kg} / \mathrm{m}^{2}$, respectively. Among under-reporters, the association was significant for the portion size of only high-fibre breakfast cereals. A statistically significant association was observed between portion size and BMI for a limited number of highenergy-dense food types.

\section{Association between $\mathrm{BMI}$ and portion size of beverages}

The portion size of high-energy soft drinks (carbonated) was positively associated with BMI. This was significant among all adolescents after adjusting for age, sex and misreporting, as well as among under-reporters; however, there was no 


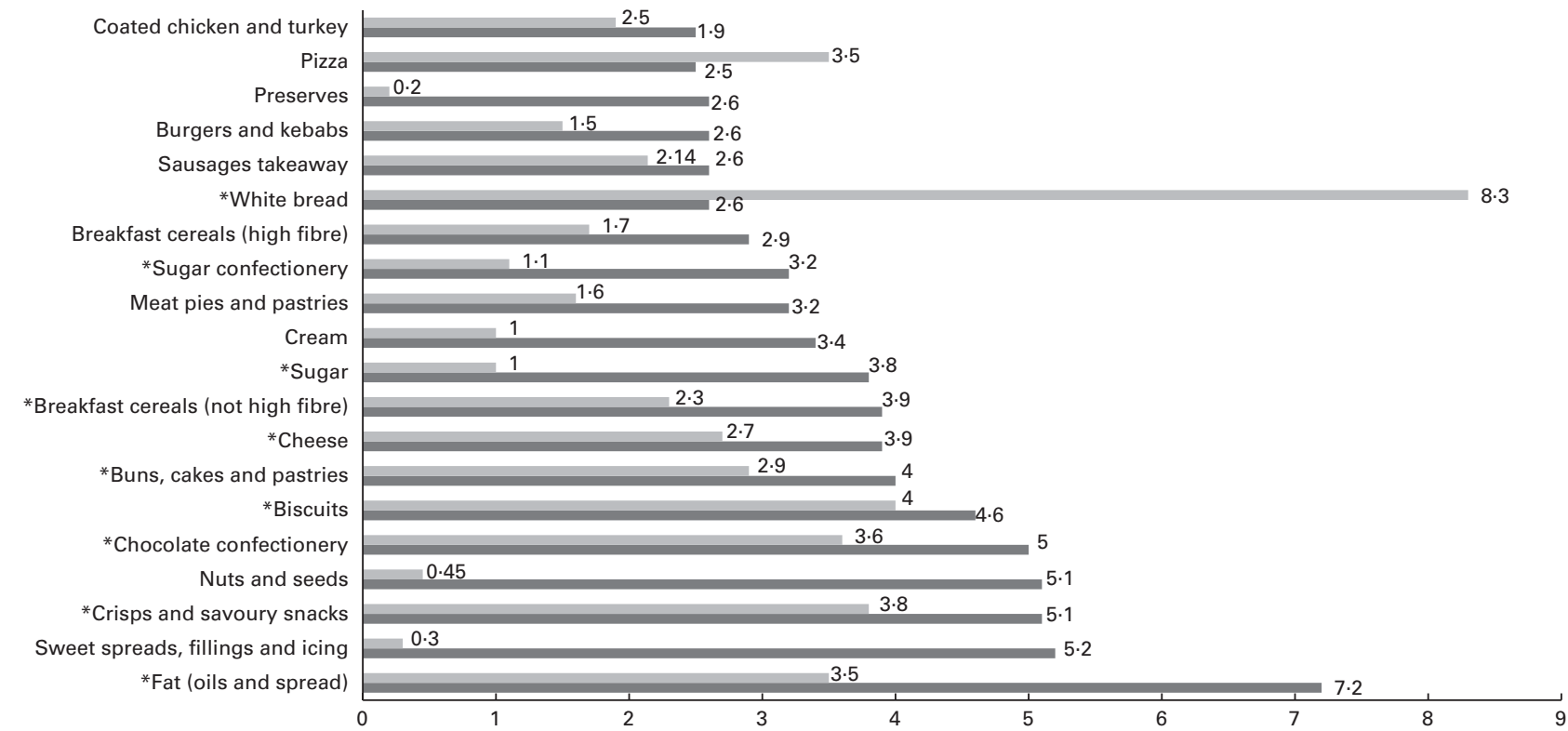

Fig. 1. The twenty most energy-dense food groups, in order of increasing energy density, consumed by British adolescents and their contribution to the average energy intake (EI) of a consumer only. $\square$, Percentage of food groups contributing to El; $\square$, energy density of food (kcal/g; $1 \mathrm{kcal}=4.2 \mathrm{~kJ})$. ${ }^{*}$ Most commonly consumed foods by adolescents.

Table 3. Food portion size $(\mathrm{g})$ and beverage portion size $(\mathrm{ml})$ for all adolescents (11-18 years) who participated in the National Diet and Nutrition Survey ${ }^{\star}$ (Number of adolescents who consumed this food, mean values and $95 \%$ confidence intervals)

\begin{tabular}{|c|c|c|c|c|c|c|c|c|c|}
\hline \multirow[b]{2}{*}{ Food groups $(\mathrm{g}) \dagger$} & \multicolumn{3}{|c|}{ All adolescents } & \multicolumn{3}{|c|}{ Normal-weight adolescents } & \multicolumn{3}{|c|}{ Overweight adolescents } \\
\hline & $n$ & Mean & $95 \% \mathrm{Cl}$ & $n$ & Mean & $95 \% \mathrm{Cl}$ & $n$ & Mean & $95 \% \mathrm{Cl}$ \\
\hline Fat & 636 & $10 \cdot 7$ & $10 \cdot 3,11 \cdot 2$ & 418 & $10 \cdot 9$ & $10.3,11.5$ & 218 & $10 \cdot 3$ & $9 \cdot 6,11 \cdot 1$ \\
\hline Sweet spreads, fillings and icing & 60 & $23 \cdot 2$ & $19 \cdot 3,27 \cdot 2$ & 44 & $24 \cdot 8$ & $19.5,29.9$ & 16 & $19 \cdot 1$ & $15 \cdot 4,22 \cdot 7$ \\
\hline Crisps and savoury snacks & 447 & $30 \cdot 2$ & $28 \cdot 6,31 \cdot 6$ & 294 & $30 \cdot 2$ & $28.5,31.8$ & 153 & $27 \cdot 8$ & $27 \cdot 8,32 \cdot 9$ \\
\hline Nuts and seeds & 85 & $28 \cdot 7$ & $23.4,33.9$ & 60 & $27 \cdot 6$ & $21 \cdot 2,34 \cdot 0$ & 25 & $31 \cdot 2$ & $21 \cdot 4,41 \cdot 1$ \\
\hline Chocolate confectionery & 378 & $39 \cdot 3$ & $35 \cdot 7,42 \cdot 8$ & 246 & 40.5 & $35 \cdot 3,45 \cdot 8$ & 132 & $36 \cdot 9$ & $34 \cdot 0,39 \cdot 9$ \\
\hline Biscuits & 385 & 37.4 & $34 \cdot 6,40 \cdot 2$ & 256 & $36 \cdot 3$ & $33.7,38.9$ & 129 & 39.4 & $33 \cdot 0,45 \cdot 9$ \\
\hline Buns, cakes and pastries & 344 & 64.9 & $61 \cdot 1,68 \cdot 8$ & 222 & $66 \cdot 4$ & $61 \cdot 6,71 \cdot 1$ & 122 & $62 \cdot 3$ & $55.5,68.9$ \\
\hline Cheese & 418 & $37 \cdot 0$ & $34 \cdot 8,39 \cdot 1$ & 261 & $38 \cdot 2$ & $35 \cdot 3,41 \cdot 0$ & 157 & 34.9 & $31.5,38 \cdot 4$ \\
\hline Breakfast cereals (not high fibre) & 285 & $39 \cdot 8$ & $38.0,41 \cdot 5$ & 191 & $40 \cdot 8$ & $38.7,42.9$ & 94 & 37.7 & $34 \cdot 8,40 \cdot 6$ \\
\hline Sugar & 335 & $10 \cdot 0$ & $9 \cdot 3,10 \cdot 7$ & 222 & $10 \cdot 5$ & $9 \cdot 6,11 \cdot 4$ & 113 & $9 \cdot 1$ & $7 \cdot 9,10 \cdot 2$ \\
\hline Cream & 66 & $32 \cdot 1$ & $27 \cdot 1,37 \cdot 1$ & 43 & 30.5 & $24 \cdot 7,36 \cdot 4$ & 23 & $35 \cdot 1$ & $25 \cdot 3,44 \cdot 9$ \\
\hline Meat pies and pastries & 141 & $115 \cdot 0$ & $104 \cdot 1,125 \cdot 9$ & 90 & $116 \cdot 8$ & $102 \cdot 7,130 \cdot 8$ & 51 & 111.8 & $94 \cdot 0,129 \cdot 7$ \\
\hline Sugar confectionery & 229 & $42 \cdot 2$ & $36 \cdot 7,47 \cdot 7$ & 140 & $46 \cdot 8$ & $39.5,54.1$ & 89 & 35 & $26 \cdot 8,43 \cdot 1$ \\
\hline High-fibre breakfast cereals & 221 & 53.7 & $48 \cdot 1,59.4$ & 149 & 52.4 & $45 \cdot 8,59 \cdot 1$ & 72 & $56 \cdot 4$ & $45 \cdot 6,67 \cdot 1$ \\
\hline Preserves & 95 & $20 \cdot 0$ & $17 \cdot 8,22 \cdot 3$ & 71 & $20 \cdot 2$ & $17 \cdot 4,23 \cdot 0$ & 24 & 19.5 & $16 \cdot 0,23 \cdot 0$ \\
\hline Sausages & 240 & 112.5 & $105 \cdot 1,119.9$ & 157 & 118.4 & $108 \cdot 8,127 \cdot 9$ & 83 & 101.4 & $89 \cdot 9,112 \cdot 8$ \\
\hline Burgers and kebabs & 151 & 138.5 & $127 \cdot 0,149 \cdot 8$ & 94 & 136.5 & $122 \cdot 7,150 \cdot 4$ & 57 & $141 \cdot 6$ & $121 \cdot 3,161 \cdot 9$ \\
\hline White bread & 556 & $72 \cdot 3$ & $69 \cdot 9,74 \cdot 8$ & 357 & $72 \cdot 9$ & $69.7,75.9$ & 199 & 71.4 & $67 \cdot 4,75 \cdot 4$ \\
\hline Pizza & 233 & $206 \cdot 5$ & $188 \cdot 0,224 \cdot 9$ & 158 & $213 \cdot 4$ & $189 \cdot 0,237 \cdot 8$ & 75 & 191.9 & $166 \cdot 3,217 \cdot 6$ \\
\hline Coated chicken and turkey & 209 & $118 \cdot 8$ & $111 \cdot 5,126 \cdot 0$ & 136 & $117 \cdot 6$ & $108 \cdot 5,126 \cdot 8$ & 73 & $120 \cdot 9$ & $108 \cdot 6,133 \cdot 2$ \\
\hline \multicolumn{10}{|l|}{ Beverages (ml) } \\
\hline Other milk & 88 & 288.9 & $254 \cdot 0,323 \cdot 9$ & 63 & 295.8 & $254 \cdot 2,337 \cdot 4$ & 25 & $271 \cdot 7$ & $203 \cdot 2,340 \cdot 3$ \\
\hline Whole milk & 133 & $143 \cdot 3$ & $126 \cdot 7,159 \cdot 8$ & 99 & 139.8 & $121 \cdot 5,158 \cdot 1$ & 34 & 153.4 & $115 \cdot 0,191 \cdot 7$ \\
\hline Semi-skimmed milk & 420 & $116 \cdot 9$ & $109 \cdot 9,124 \cdot 0$ & 272 & $116 \cdot 3$ & $107 \cdot 9,124 \cdot 8$ & 148 & $118 \cdot 1$ & $105 \cdot 3,130 \cdot 9$ \\
\hline Carbonated soft drinks (not low energy) & 401 & 337.4 & $326.4,348.5$ & 266 & $332 \cdot 7$ & $319 \cdot 6,345 \cdot 9$ & 135 & $346 \cdot 8$ & $326 \cdot 5,367 \cdot 0$ \\
\hline Fruit juice (100\%) & 315 & 241.9 & $227 \cdot 4,256 \cdot 5$ & 212 & 236.4 & $220 \cdot 4,252 \cdot 3$ & 103 & 253.4 & $222 \cdot 9,283 \cdot 9$ \\
\hline Citrus fruit (not canned) & 115 & $95 \cdot 1$ & $84 \cdot 7,105 \cdot 6$ & 72 & $100 \cdot 7$ & $86 \cdot 8,114 \cdot 7$ & 43 & $85 \cdot 8$ & $70 \cdot 1,101 \cdot 4$ \\
\hline
\end{tabular}

${ }^{*}$ No adjustments for under-reporting were made.

† Information about food group classification is given in online supplementary Appendix 1. 
Table 4. Association between BMI and portion size of each of the twenty most energy-dense foods consumed by adolescents (Number of adolescents, change in BMI values and $95 \%$ confidence intervals)

\begin{tabular}{|c|c|c|c|c|c|c|c|c|c|c|c|c|c|}
\hline \multirow[b]{2}{*}{ Food groups $(10 \mathrm{~g})$} & \multirow[b]{2}{*}{ ED } & \multicolumn{4}{|c|}{ All adolescents* } & \multicolumn{4}{|c|}{ Normal reporters $\dagger$} & \multicolumn{4}{|c|}{ Under-reporters $†$} \\
\hline & & $n$ & $\begin{array}{l}\text { Changes } \\
\text { in BMI§ }\end{array}$ & $95 \% \mathrm{Cl}$ & $P$ & $n$ & $\begin{array}{l}\text { Changes } \\
\text { in BMI§ }\end{array}$ & $95 \% \mathrm{Cl}$ & $P$ & $n$ & $\begin{array}{l}\text { Changes } \\
\text { in BMI§ }\end{array}$ & $95 \% \mathrm{Cl}$ & $P$ \\
\hline Fat (oils and spreads) & $7 \cdot 2$ & 636 & 0.920 & $-0.25,2 \cdot 1$ & 0.86 & 171 & 0.102 & $-0.32,0.52$ & 0.63 & 465 & 0.168 & $-0.33,0.66$ & 0.51 \\
\hline Sweet spreads, fillings and icing & $5 \cdot 2$ & 60 & -0.175 & $-0.66,0.31$ & 0.47 & 26 & -0.317 & $-1.4,0.72$ & 0.53 & 34 & 0.033 & $-0.65,0.72$ & 0.92 \\
\hline Crisps and savoury snacks & $5 \cdot 1$ & 447 & $0 \cdot 121$ & $-0.13,0.38$ & 0.35 & 140 & -0.003 & $-0.32,0.31$ & 0.98 & 307 & 0.152 & $-0.19,0.49$ & 0.38 \\
\hline Nuts and seeds & $5 \cdot 1$ & 85 & 0.102 & $-0.16,0.36$ & 0.44 & 34 & -0.111 & $-0.60,0.38$ & 0.65 & 51 & $0 \cdot 164$ & $-0.16,0.50$ & 0.32 \\
\hline Chocolate confectionery & $5 \cdot 0$ & 378 & 0.025 & $-0.09,0.14$ & 0.66 & 128 & 0.062 & $-0.09,0.22$ & 0.43 & 250 & 0.011 & $-0.14,0.16$ & 0.88 \\
\hline Biscuits & 4.6 & 385 & 0.053 & $-0.10,0.21$ & 0.50 & 118 & 0.283 & $0.01,0.56$ & $0.04 \|$ & 267 & 0.018 & $-0.17,0.21$ & 0.84 \\
\hline Buns, cakes and pastries & 4.0 & 344 & -0.049 & $-0.18,0.08$ & 0.45 & 118 & 0.185 & $0.05,0.33$ & $0.01 \|$ & 226 & -0.098 & $-0.26,0.068$ & 0.24 \\
\hline Cheese & 3.9 & 418 & -0.080 & $-0.26,0.11$ & 0.40 & 118 & 0.258 & $0.04,0.52$ & $0.05 \|$ & 300 & -0.204 & $-0.44,0.03$ & 0.08 \\
\hline Breakfast cereals (not high fibre) & 3.9 & 285 & 0.037 & $-0.29,0.37$ & 0.83 & 91 & -0.010 & $-0.34,0.32$ & 0.95 & 194 & 0.744 & $-0.43,0.57$ & 0.77 \\
\hline Sugar & 3.8 & 335 & -0.260 & $-0.92,0.39$ & 0.43 & 82 & 0.253 & $-0.89,1.4$ & 0.66 & 253 & -0.342 & $-1.1,0.43$ & 0.38 \\
\hline Cream & 3.4 & 66 & 0.622 & $0.14,1 \cdot 11$ & $0.01 \|$ & 22 & 0.747 & $0.02,1.5$ & $0.04 \|$ & 44 & 0.424 & $-0.29,1.1$ & $1 \cdot 14$ \\
\hline Meat pies and pastries & $3 \cdot 2$ & 141 & 0.021 & $-0.01,0.14$ & 0.73 & 42 & -0.112 & $-0.29,0.07$ & 0.21 & 99 & 0.089 & $-0.06,0.24$ & 0.23 \\
\hline Sugar confectionery & $3 \cdot 2$ & 229 & -0.055 & $-0.19,0.08$ & 0.41 & 83 & -0.001 & $-0.12,0.12$ & 0.99 & 146 & -0.112 & $-0.34,0.11$ & 0.29 \\
\hline Breakfast cereals (high fibre) & 2.9 & 221 & 0.138 & $0.03,0.25$ & $0.01 \|$ & 64 & 0.070 & $-0.10,0.21$ & 0.33 & 157 & 0.165 & $0.02,0.31$ & $0.02 \|$ \\
\hline Preserves & $2 \cdot 6$ & 95 & -0.040 & $-0.79,0.71$ & 0.92 & 26 & $0 \cdot 126$ & $-0.81,1 \cdot 1$ & 0.78 & 69 & -0.247 & $-1 \cdot 3,0.79$ & 0.64 \\
\hline Sausages & $2 \cdot 6$ & 240 & -0.061 & $-0.16,0.04$ & 0.22 & 74 & 0.080 & $-0.04,0.20$ & $0 \cdot 19$ & 166 & -0.127 & $-0.27,0.01$ & 0.06 \\
\hline Burgers and kebabs & $2 \cdot 6$ & 181 & 0.020 & $-0.08,0.12$ & 0.69 & 49 & 0.022 & $-0.10,0.13$ & 0.69 & 102 & 0.022 & $-0.12,0.16$ & 0.75 \\
\hline White bread & $2 \cdot 6$ & 556 & -0.012 & $-0.13,0.11$ & 0.85 & 152 & -0.013 & $-0.18,0.15$ & 0.87 & 404 & 0.001 & $-0.15,0.16$ & 0.99 \\
\hline Pizza & $2 \cdot 5$ & 233 & -0.001 & $-0.04,0.04$ & 0.96 & 73 & 0.003 & $-0.04,0.04$ & 0.98 & 160 & 0.002 & $-0.05,0.06$ & 0.93 \\
\hline Coated chicken and turkey & 2.5 & 209 & 0.024 & $-.10,0.12$ & 0.64 & 62 & 0.090 & $-0.03,0.21$ & 0.15 & 147 & -0.004 & $-0.14,0.13$ & 0.96 \\
\hline
\end{tabular}

ED, energy density

and misreporting-adjusted regression (model 2).

$\dagger$ Age- and sex-adjusted regression (model 3).

$\ddagger E D$ of food group.

$\S$ Changes in $\mathrm{BMI}\left(\mathrm{kg} / \mathrm{m}^{2}\right)$ per each $10 \mathrm{~g}$.

$\| P<0.05$. 
association between beverage portion size and BMI among normal reporters (Table 5). The portion size of the food group 'Other milk' (which includes flavoured milk and hot chocolate) was negatively associated with the BMI of adolescents.

\section{Discussion}

The findings of the present study indicate a positive association between BMI and total EI and macronutrient intake. After stratifying the sample by misreporting, a stronger association was observed in normal reporters than in under-reporters. Similar findings were recorded when the association between weight and EI was tested (data not shown), as some may argue that individuals with a larger body size require a higher EI. However, BMI is a better measure of adiposity for all childhood age groups, and the advantage of using BMI raw values is that arbitrary cut points are not required to define obesity ${ }^{(36)}$. Furthermore, exclusion of misreporters provides the most appropriate model to examine crosssectional associations between $\mathrm{EI}$ and $\mathrm{BMI}^{(37)}$. Cross-sectional surveys of adolescents have reported contradictory results on the association between EI and BMI; for example, in the large National Health and Nutrition Examination Survey study, overweight and obese adolescents reported consuming lesser energy than their normal-weight peers ${ }^{(38)}$. Similar to these findings, an Australian study of 2460 boys and girls aged 5-17 years has reported that BMI $Z$-score is weakly but significantly associated with total EI among all age groups when misreporting is taken into account ${ }^{(39)}$.

Among the few longitudinal studies carried out in adolescents $^{(14)}$, a study comprising 6149 girls and 4620 boys aged 9-14 years from across the USA has found that EI during 1 year is positively associated with an increase in BMI $\left(\mathrm{kg} / \mathrm{m}^{2}\right)$ when taking growth and development into account ${ }^{(36)}$.

The average EI reported in the NDNS series is consistently less than the level indicated by the estimated average requirements $^{(40)}$. In reality, average EI in UK adolescents is more likely to exceed energy needs, as the evidence shows that the number of adolescents who are classified as overweight and obese is increasing. Thus, under-reporting of food intake may explain this paradox ${ }^{(40)}$. All current methods of dietary intake assessment are prone to error, although research is ongoing to find more valid methods for this age group.

Some studies that have investigated the relationship between BMI and diet composition suggest that macronutrients (protein, carbohydrates and fat) may play an important role in the development of obesity in young people ${ }^{(41,42)}$. However, conflicting results have been reported ${ }^{(14)}$. One study has demonstrated that obese adolescents consume more energy from fat and protein and less from carbohydrates when compared with normal-weight adolescents ${ }^{(13)}$. In the present study, total intake from fat, carbohydrates, protein, and sugars (in g) was found to be positively associated with BMI in the whole sample and normal reporters only. There was no association between the percentage of EI from each macronutrient and BMI in either of these groups. Neither of these associations was observed in under-reporters. This is in agreement with the findings of a study carried out by 
Elliott et $a{ }^{(39)}$, in which no evidence for an association between BMI and percentage of EI from fat, carbohydrates and protein was found, although participants with a higher BMI consumed significantly more energy than lean counterparts.

The present results indicated that the lack of an association between the percentage of EI from macronutrients and BMI was not a direct result of misreporting, and it is more likely that EI influences the development of obesity rather than the source of energy. Similarly, one longitudinal study has also found no significant relationship between the percentage EI from any macronutrient and weight gain ${ }^{(43)}$. In Germany, different dietary patterns during childhood and adolescence could not explain the development of obesity in a long-term evaluation $^{(44,45)}$.

The portion sizes of only a limited number of food groups among the twenty most energy-dense food groups were positively associated with BMI in the whole sample, and there were differences between normal reporters and under-reporters. The portion sizes of biscuits, cakes and cheese were significantly positively associated with BMI in normal reporters but not in under-reporters. The portion sizes of cream and high-fibre breakfast cereals were positively associated with BMI among all adolescents, and a significant association was observed in underreporters for the latter food group. The portion size of carbonated soft drinks (not low energy) was positively associated with BMI among all adolescents and under-reporters but not among normal reporters.

Similarly, a cross-sectional study of young French children showed that overweight in children was positively correlated with the portion sizes of biscuits and sweetened pastries ${ }^{(12)}$. Additionally, positive trends were observed for croissant-like pastries and other sweetened pastries, although they were not significant ${ }^{(12)}$. According to Church $^{(10)}$, there have been minimal changes in the weight of traditional biscuits and cakes in the UK since the 1990s. However, luxury cookies and those from retail food service outlets are larger than traditional ones (traditional cookies weigh 10-12 g, while a luxury cookie, e.g. that of Starbucks, weighs about $110 \mathrm{~g}$ ) and they are likely to be more energy dense than traditional ones ${ }^{(10)}$. Also, there is some evidence of an increase in the range of confectionery items available in king and giant sizes in the $\mathrm{UK}^{(24)}$. In fact, when provided in large portion sizes, this food choice could significantly contribute to weight gain $^{(46)}$

Moreover, the portion sizes of other foods such as savoury snacks and confectionery were found to be not associated with BMI, which may be because these foods are sold in small or standard portion sizes, so all adolescents consumed similar portion sizes of these foods. Other researchers have found no statistically significant difference in the number of savoury snack servings/d between obese and normal-weight children $^{(8-10,47)}$. In one study, EI from candy, packed goods and ice cream has been found to be significantly greater in normal-weight adolescents than in obese adolescents, although under-reporting cannot be ruled out ${ }^{(13)}$.

Although consumption of ready-to-eat cereals has been reported to be associated with a lower BMI in children aged
$4-12$ years $^{(48)}$ and adults aged $35-64$ years $^{(49)}$, in the present study, we found that the portion size of high-fibre breakfast cereals was positively associated with BMI among all adolescents and under-reporters and not significantly associated among normal reporters. This may be because of the incorporation of nuts, honey, sugar and fruit in the high-fibre breakfast cereals, which made them more energy dense. This was also perhaps due to under-reporters being more likely to be overweight or obese than normal reporters; this has also been found in other studies ${ }^{(50)}$. Obese under-reporters may be more likely to be following or at least report eating a healthy diet at the time data were collected. A previous study ${ }^{(21)}$ has found no differences in reported breakfast cereal and savoury snack intake between normal-weight and overweight participants using NDNS-1997 and Northern Ireland-2005 data. However, this may be because the authors did not consider confounders in their analysis.

With regard to beverages, the scientific literature on the effects of carbonated soft drink (not low energy) consumption in relation to obesity is varied. Several reviews have provided evidence regarding the hypothesis that increased energy from sweetened beverages leads to increased weight. However, results of trials to reduce sugar-sweetened beverage intake and effect on the risk of obesity are inconsistent in children, perhaps due to a failure to control for confounders and methodological limitations ${ }^{(51-54)}$. Similar to the findings of the present study, other cross-sectional studies have reported significant positive associations between soft drink intake and $\mathrm{BMI}^{(55-58)}$, but the strength of the association is generally attenuated compared with the results of longitudinal studies ${ }^{(59-61)}$.

In the USA, sweetened drinks (soda, energy drinks and sports drinks) are the top energy sources in the adolescent diet $(946 \mathrm{~kJ}(226 \mathrm{kcal}) / \mathrm{d})^{(62)}$. In the UK, the contribution of non-alcoholic beverages to EI increased from 7\% in 1997 to $9 \%$ in 2008-2011, of which soft drinks (not low energy) were the largest contributors (SA Albar, NA Alwan, CEL Evans and JE Cade, unpublished results). In a prospective, observational analysis, it has been found that with each additional $12 \mathrm{oz}$ soda that children consumed a day, the odds of becoming obese over 1.5 years increased by $60 \%$ after follow-up ${ }^{(59)}$. According to Glickman et al. ${ }^{(62)}$ the rising consumption of sweetened drinks has been a major contributor to the obesity epidemic. The intake of liquid carbohydrates, or 'liquid candy', causes less satiety compared with that of solid carbohydrates, which leads to an increase in total long-term EI as energy from liquids may not be compensated by subsequent meals ${ }^{(63,64)}$.

Milk is promoted as a healthy beverage. However, some researchers believe that protein in dairy products may cause weight gain ${ }^{(65)}$. Others state that dairy Ca promotes weight loss ${ }^{(66)}$. The results of the present study indicated that the portion sizes of other milk products (e.g. soya, goat, sheep, condensed and dried milk) were inversely associated with BMI among all adolescents and under-reporters, but we did not observe the same trend for plain whole milk or semiskimmed milk. A French cross-sectional study has found that the portion sizes of liquid dairy products (milk, milkshakes and yogurt drinks) are negatively associated with overweight 
in children (aged 7-11 years) ${ }^{(12)}$. Conversely, the portion size of cheese was found to be positively associated with BMI among normal reporters in the present study. A longitudinal US study among 12829 adolescents aged 11-14 years concluded that drinking large amounts of milk, skimmed milk and dairy Ca may provide excess energy, resulting in an increase in body weight ${ }^{(65)}$. Further research is needed to investigate and explain the role of dairy product intake in obesity risk.

Although in the present study self-reported dieters were excluded and adjustment for misreporting was undertaken in the whole sample, the portion sizes of a limited number of food groups were found to be associated with BMI. This may be due to several factors. Obese adolescents and even adolescents of normal weight tend to underestimate their dietary intake, either consciously or unconsciously ${ }^{(67,68)}$, and they are frequently on a special diet to control their body weight ${ }^{(14)}$. Additionally, the study sample may still include adolescents who might have limited their food intake during the study without declaring it. Research suggests that people report or under-report the intake of food that is perceived to be unhealthy or associated with obesity ${ }^{(69)}$. From Table 3, it can be observed that the average portion sizes of some energy-dense foods consumed by normal-weight adolescents were larger than those consumed by overweight/obese adolescents. Furthermore, the findings of the present study did not indicate an association between the percentage of EI from macronutrients and BMI, which may explain why fewer associations were observed between the portion sizes of high-energy-dense foods and BMI in the whole sample.

The present study has notable limitations. First, the crosssectional nature of the study prevented the determination of the direction of association. A high percentage of underreporters were observed, and this had been previously reported in the $1997 \mathrm{NDNS}^{(70)}$ among adolescents, where a weighed record was used. Estimated FPS have been used in the recent NDNS (2008-2011) to minimise respondent burden; however, this may have reduced the accuracy of the portion sizes reported. Measuring young people's dietary intake is challenging and less likely to give accurate $\operatorname{FPS}^{(50)}$. Adolescents are less interested, less motivated and less cooperative compared with other age groups ${ }^{(50,71)}$. However, it has been found that adolescents preferred dietary intake assessment methods that use new technology over the pen-and-paper method ${ }^{(72)}$. Tailoring dietary intake assessment methods to the specific needs of the population under investigation will greatly improve the accuracy of dietary records ${ }^{(28)}$. Thus, further work is required to develop and test dietary intake assessment methods that use new technology to obtain better-quality and more accurate dietary records from adolescents.

An additional limitation is the lack of consensus in the definition of high-energy-dense foods and beverages. The British Nutrition Foundation has classified foods that contain $0-2.5 \mathrm{~kJ} / \mathrm{g}(0-0.6 \mathrm{kcal} / \mathrm{g})$ as very-low-energy-dense foods; $2.55-6.3 \mathrm{~kJ} / \mathrm{g}(0.61-1.5 \mathrm{kcal} / \mathrm{g})$ as low; $6.7-17 \mathrm{~kJ} / \mathrm{g}$ $(1.6-4 \mathrm{kcal} / \mathrm{g})$ as medium; and $17 \cdot 1-38 \mathrm{~kJ} / \mathrm{g}(4 \cdot 1-9 \mathrm{kcal} / \mathrm{g})$ as high ${ }^{(73)}$. However, the medium and high classifications are wider than the World Cancer Research Fund classification, which considers foods that contain more than $9.41-11.50 \mathrm{~kJ} / \mathrm{g}$ $(2 \cdot 25-2 \cdot 75 \mathrm{kcal} / \mathrm{g})$ as high-energy-dense foods. Therefore, there is a need for more research to identify clear cut-off points of both energy-dense foods and beverages, due to the contribution of beverages to adolescents' EI.

Nevertheless, in the present study, new nationally representative data of British adolescents (NDNS 2008-2011) were used. To our knowledge, the present study is the first to examine the epidemiological relationship between the portion size of energy-dense foods and BMI among British adolescents. Other potential confounders such as age, sex and misreporting EI were taken into account and all adolescents who were dieting to lose weight were excluded to reduce the risk of bias. Also, data were stratified by misreporting to explore any potential effects of under-reporting. Therefore, the present study provides a useful insight into the association between the portion size of energy-dense foods and obesity and emphasises the importance of considering misreporting when assessing possible associations between dietary intake and variables of interest. Prospective studies with physical activity data are needed to confirm our findings.

\section{Conclusion}

In the present study carried out using a nationally representative sample of British adolescents, EI was found to more likely influence the development of obesity than the source of energy. This was significant after adjusting for misreporting and also after stratifying the sample into normal reporters and under-reporters. The portion sizes of a limited number of high-energy-dense foods (high-fibre breakfast cereals, cream and carbonated high-energy soft drinks) were found to be associated with a higher BMI among all adolescents. However, when eliminating the effect of under-reporting, larger portion sizes of a number of high-energy-dense foods, including biscuits, cheese, cream and cakes, were found to be associated with a higher BMI. The portion sizes of only high-fibre breakfast cereals and carbonated high-energy soft drinks were found to be associated with BMI among underreporters. These findings emphasise the importance of considering under-reporting when analysing adolescents' dietary intake data as it is prone to reporting error. Further improvements in dietary intake assessment methods among adolescents are required. Moreover, multiple approaches directed at adolescents to enhance their food choices and portion sizes of high-energy-dense food are necessary to prevent and control obesity among all adolescents.

\section{Supplementary material}

To view supplementary material for this article, please visit http://dx.doi.org/10.1017/S0007114514001548

\section{Acknowledgements}

S. A. A. is in receipt of a scholarship from King Abdul-Aziz University, Jeddah, Saudi Arabia. 
The authors' contributions are as follows: S. A. A. designed the study, analysed and interpreted the data, and wrote the manuscript. J. E. C., N. A. A. and C. E. L. E. assisted in designing the study and interpreting the data. All authors reviewed and approved the final manuscript.

None of the authors has any conflicts of interest to declare.

\section{References}

1. Health and Social Care Information Centre (Lifestyles Statistics) (2013) Statistics on Obesity, Physical Activity and Diet: England. London: The Health and Social Care Information Centre.

2. Reilly J (2006) Obesity in childhood and adolescence: evidence based clinical and public health perspectives. Postgrad Med J 82, 429-437.

3. Frank BH (2008) Obesity Epidemiology. New York, NY: Oxford University Press.

4. Cutler D, Glaeser E \& Shapiro J (2003) Why Have Americans Become More Obese?. Cambridge, MA: National Bureau of Economic Research.

5. Huang TTK \& McCrory MA (2005) Dairy intake, obesity, and metabolic health in children and adolescents: knowledge and gaps. Nutr Rev 63, 71-80.

6. Rennie KL, Johnson L \& Jebb SA (2005) Behavioural determinants of obesity. Best Pract Res Clin Endocrinol Metab 19 , $343-358$

7. Nicklas TA, Yang S-J, Baranowski T, et al. (2003) Eating patterns and obesity in children: The Bogalusa Heart Study. Am J Prev Med 25, 9-16.

8. Nielsen S \& Popkin BM (2003) Patterns and trends in food portion sizes, 1977-1998. JAMA 289, 450-453.

9. Steenhuis IH, Leeuwis FH \& Vermeer WM (2010) Small, medium, large or supersize: trends in food portion sizes in The Netherlands. Public Health Nutr 13, 852-857.

10. Church S (2008) Trends in Portion Sizes in the UK - A Preliminary Review of Published Information. London: Food Standards Agency.

11. Benson C (2009) Increasing portion size in Britain. Soc Biol Hum Aff 74, 4-20.

12. Lioret S, Volatier J, Lafay L, et al. (2007) Is food portion size a risk factor of childhood overweight? Eur J Clin Nutr $\mathbf{6 3}$, 382-391.

13. Bandini LG, Vu D, Must A, et al. (1999) Comparison of highcalorie, low-nutrient-dense food consumption among obese and non-obese adolescents. Obes Res 7, 438-443.

14. Rodríguez G \& Moreno LA (2006) Is dietary intake able to explain differences in body fatness in children and adolescents? Nutr Metab Cardiovasc Dis 16, 294-301.

15. Westerterp-Plantenga M (2001) Analysis of energy density of food in relation to energy intake regulation in human subjects. Br J Nutr 85, 351-361.

16. World Cancer Research Fund (WCRF UK) (2007) Energy density: finding the balance for cancer prevention. http://www.wcrf-uk. org/PDFs/EnergyDensity.pdf (accessed 13 February 2014).

17. Ello-Martin JA, Ledikwe JH \& Rolls BJ (2005) The influence of food portion size and energy density on energy intake: implications for weight management. Am J Clin Nutr 82, Suppl. 1, 236S-241S.

18. Kral TVE \& Rolls BJ (2004) Energy density and portion size: their independent and combined effects on energy intake. Physiol Behav 82, 131-138.

19. Rolls BJ, Morris EL \& Roe LS (2002) Portion size of food affects energy intake in normal-weight and overweight men and women. Am J Clin Nutr 76, 1207-1213.
20. Ledikwe JH, Ello-Martin JA \& Rolls BJ (2005) Portion sizes and the obesity epidemic. J Nutr 135, 905-909.

21. Kerr MA, Rennie KL, McCaffrey TA, et al. (2009) Snacking patterns among adolescents: a comparison of type, frequency and portion size between Britain in 1997 and Northern Ireland in 2005. Br J Nutr 101, 122-131.

22. Forshee RA, Anderson PA \& Storey ML (2008) Sugar-sweetened beverages and body mass index in children and adolescents: a meta-analysis. Am J Clin Nutr 87, 1662-1671.

23. Gibson S \& Neate D (2007) Sugar intake, soft drink consumption and body weight among British children: further analysis of National Diet and Nutrition Survey data with adjustment for under-reporting and physical activity. Int $J$ Food Sci Nutr 58, 445-460.

24. Wrieden W, Gregor A \& Barton K (2008) Have food portion sizes increased in the UK over the last 20 years? Proc Nutr Soc 67, E211.

25. UK Data Service Discover (2012) National Diet and Nutrition Survey, 2008-2011. Funded by the Department of Health (DH) in England and the UK Food Standards Agency (FSA).

26. Bates B, Lennox A \& Olson A, et al. (2012) National Diet and Nutrition Survey: headline results from year 1, 2 and 3 (combined) of the rolling programme (2008/2009-2010/11). http:// www.natcen.ac.uk/media/175123/national-diet-and-nutritionsurvey-years-1-2-and-3.pdf (accessed February 2012).

27. Foster E, Matthews JN, Lloyd J, et al. (2008) Children's estimates of food portion size: the development and evaluation of three portion size assessment tools for use with children. BrJ Nutr 99, 175-184.

28. Foster E, Adamson AJ, Anderson AS, et al. (2009) Estimation of portion size in children's dietary assessment: lessons learnt. Eur J Clin Nutr 63, Suppl. 1, S45-S49.

29. Food Standards Agency (2011) Appendix P: main and subsidiary food groups. http://www.natcen.ac.uk/media/ 175123/national-diet-and-nutrition-survey-years-1-2-and-3.pdf (accessed 21 January 2012)

30. Food Standards Agency (2002) McCance and Widdowson's The Composition of Food, 6th ed. Cambridge, UK: Royal Society of Chemistry.

31. Wrieden WL, Longbottom PJ, Adamson AJ, et al. (2008) Estimation of typical food portion sizes for children of different ages in Great Britain. BrJ Nutr 99, 1344-1353.

32. Rolls BJ, Drewnowski A \& Ledikwe JH (2005) Changing the energy density of the diet as a strategy for weight management. J Am Diet Assoc 105, 98-103.

33. Cole TJ, Freeman JV \& Preece MA (1995) Body mass index reference curves for the UK, 1990. Arch Dis Child 73, 25-29.

34. Schofield WN (1985) Predicting basal metabolic rate, new standards and review of previous work. Hum Nutr Clin Nutr 39, Suppl. 1, 5-41.

35. Torun B, Davies P, Livingstone M, et al. (1996) Energy requirements and dietary energy recommendations for children and adolescents 1 to 18 years old. Eur J Clin Nutr 50, S37-S81.

36. Berkey CS, Rockett HR, Field AE, et al. (2000) Activity, dietary intake, and weight changes in a longitudinal study of preadolescent and adolescent boys and girls. Pediatrics 105, E56.

37. Rangan AM, Flood VM \& Gill TP (2011) Misreporting of energy intake in the 2007 Australian Children's Survey: identification, characteristics and impact of misreporters. Nutrients 3, 186-199.

38. Hillier FC (2010) The development and evaluation of a novel online tool for assessing dietary intake and physical activity levels for use in adult populations. PhD Thesis, Durham University. 
39. Elliott S, Truby H, Lee A, et al. (2011) Associations of body mass index and waist circumference with: energy intake and percentage energy from macronutrients, in a cohort of Australian children. Nutr J 10, 58.

40. Scientific Advisory Committee on Nutrition (SACN) (2012) Dietary Reference Values for Energy. London: The Stationery Office.

41. Gillis L, Kennedy L, Gillis A, et al. (2002) Relationship between juvenile obesity, dietary energy and fat intake and physical activity. Int J Obes Relat Metab Disord 26, 458-463.

42. Maffeis C, Provera S, Filippi L, et al. (2000) Distribution of food intake as a risk factor for childhood obesity. Int $J$ Obes Relat Metab Disord 24, 75-80.

43. Magarey A, Daniels L, Boulton T, et al. (2001) Does fat intake predict adiposity in healthy children and adolescents aged 2-15 y? A longitudinal analysis. Eur J Clin Nutr 55, 471-481.

44. Alexy U, Sichert-Hellert W, Kersting M, et al. (2004) Pattern of long-term fat intake and BMI during childhood and adolescence - results of the DONALD Study. Int $J$ Obes Relat Metab Disord 28, 1203-1209.

45. Alexy U, Sichert-Hellert W \& Kersting M (2002) Fifteen-year time trends in energy and macronutrient intake in German children and adolescents: results of the DONALD study. Br J Nutr 87, 595-604.

46. Young LR \& Nestle M (2002) The contribution of expanding portion sizes to the US obesity epidemic. Am J Public Health 92, 246-249.

47. Loaloraber H \& Nielsen J (2013) Teenage usability: designing teen-targeted websites. http://www.nngroup.com/topic/ web-usability/all/ (accessed 14 January 2014)

48. Albertson AM, Anderson GH, Crockett SJ, et al. (2003) Ready-to-eat cereal consumption: its relationship with BMI and nutrient intake of children aged 4 to 12 years. $\mathrm{J} \mathrm{Am}$ Diet Assoc 103, 1613-1619.

49. Albertson A, Goebel M, Kolberg L, et al. (2001) Breakfast and ready-to-eat cereal consumption habits of adult women in the US population and the relationship with energy intake and body mass index. Obes Res 9, Suppl. 3, 183 S.

50. Livingstone MBE, Robson PJ \& Wallace JMW (2004) Issues in dietary intake assessment of children and adolescents. Br J Nutr 92, Suppl. 2, S213-S222.

51. Bachman CM, Baranowski T \& Nicklas TA (2006) Is there an association between sweetened beverages and adiposity? Nutr Rev 64, 153-174.

52. Malik VS, Schulze MB \& Hu FB (2006) Intake of sugarsweetened beverages and weight gain: a systematic review. Am J Clin Nutr 84, 274-288.

53. Pereira MA (2006) The possible role of sugar-sweetened beverages in obesity etiology: a review of the evidence. Int J Obes 30, $\mathrm{S} 28-\mathrm{S} 36$.

54. Harris JE, Gleason PM, Sheean PM, et al. (2009) An introduction to qualitative research for food and nutrition professionals. J Am Diet Assoc 109, 80-90.

55. Berkey CS, Rockett HR, Field AE, et al. (2004) Sugar-added beverages and adolescent weight change. Obes Res 12, 778-788.

56. Gillis LJ \& Bar-Or O (2003) Food away from home, sugarsweetened drink consumption and juvenile obesity. J Am Coll Nutr 22, 539-545.
57. Troiano RP, Briefel RR, Carroll MD, et al. (2000) Energy and fat intakes of children and adolescents in the United States: data from the National Health and Nutrition Examination Surveys. Am J Clin Nutr 72, Suppl. 5, 1343S-1353S.

58. Mrdjenovic G \& Levitsky DA (2003) Nutritional and energetic consequences of sweetened drink consumption in 6- to 13-year-old children. J Pediatr 142, 604-610.

59. Ludwig DS, Peterson KE \& Gortmaker SL (2001) Relation between consumption of sugar-sweetened drinks and childhood obesity: a prospective, observational analysis. Lancet 357, 505-508.

60. Phillips SM, Bandini LG, Naumova EN, et al. (2004) Energydense snack food intake in adolescence: longitudinal relationship to weight and fatness. Obes Res 12, 461-472.

61. Welsh JA, Cogswell ME, Rogers S, et al. (2005) Overweight among low-income preschool children associated with the consumption of sweet drinks: Missouri, 1999-2002. Pediatrics 115, e223-e229.

62. Glickman D, Parker L, Sim L, et al. (2012) Accelerating Progress in Obesity Prevention: Solving the Weight of the Nation. Washington, DC: National Academies Press.

63. Pan A \& Hu FB (2011) Effects of carbohydrates on satiety: differences between liquid and solid food. Curr Opin Clin Nutr Metab Care 14, 385-390.

64. DiMeglio DP \& Mattes RD (2000) Liquid versus solid carbohydrate: effects on food intake and body weight. Int $J$ Obes Relat Metab Disord 24, 794-800.

65. Berkey C, Rockett HH, Willett WC, et al. (2005) Milk, dairy fat, dietary calcium, and weight gain: a longitudinal study of adolescents. Arch Pediatr Adolesc Med 159, 543-550.

66. Zemel M (2003) Role of dietary calcium and dairy products in modulating adiposity. Lipids 38, 139-146.

67. Livingstone M \& Robson P (2000) Measurement of dietary intake in children. Proc Nutr Soc 59, 279-293.

68. Livingstone MB, Prentice AM, Coward WA, et al. (1992) Validation of estimates of energy intake by weighed dietary record and diet history in children and adolescents. Am J Clin Nutr 56, 29-35.

69. Lafay L, Mennen L, Basdevant A, et al. (2000) Does energy intake underreporting involve all kinds of food or only specific food items? Results from the Fleurbaix Laventie Ville Santé (FLVS) study. Int J Obes Relat Metab Disord 24 , 1500-1506.

70. Rennie KL, Jebb SA, Wright A, et al. (2007) Secular trends in under-reporting in young people. Br J Nutr 93, 241-247.

71. Goodwin RA, BrulÉ D, Junkins EA, et al. (2001) Development of a food and activity record and a portion-size model booklet for use by 6- to 17-year olds: a review of focus-group testing. J Am Diet Assoc 101, 926-928.

72. Boushey C, Kerr D, Wright J, et al. (2009) Use of technology in children's dietary assessment. Eur J Clin Nutr 63, S50-S57.

73. British Nutrition Foundation (2009) What is energy density? http://www.nutrition.org.uk/healthyliving/fuller/what-isenergy-density?tmpl $=$ component\&print $=1$ \&page $=($ accessed December 2012). 